\title{
Pre-pregnancy cardiovascular risk factors and racial disparities in birth outcomes: the Bogalusa Heart Study
}

\author{
Emily W. Harville ${ }^{1 *}$ D, Leann Myers², Tian Shu', Maeve E. Wallace ${ }^{3}$ and Lydia A. Bazzano ${ }^{1}$
}

\begin{abstract}
Background: Racial disparities in birth outcomes are mirrored in cardiovascular health. Recently there have been calls for more attention to preconception and interconceptional health in order to improve birth outcomes, including as a strategy to reduce black-white disparities.

Methods: As part of a larger study of cardiovascular and reproductive health ("Bogalusa Babies"), female participants were linked to their children's birth certificates for Louisiana, Mississippi, and Texas births from 1982 to 2009. Three thousand and ninety-five women were linked to birth certificate data. Birth outcomes were defined as low birthweight (LBW) birthweight < $2500 \mathrm{~g}$; preterm birth (PTB), > 3 weeks early; small for gestational age (SGA), <10th percentile for gestational age (percentiles based on study population); large for gestational age (LGA) >90th percentile for gestational age]. Cardiovascular measures (blood pressure, lipids, glucose, insulin) at the visit closest in time but prior to the pregnancy was examined as predictors of birth outcomes using logistic models adjusted for covariates.

Results: Only a few cardiovascular risk factors were associated with birth outcomes. Triglycerides were associated with higher risk of LBW among whites (aOR 1.05, 95\% 1.01-1.10). Higher glucose was associated with a reduction in risk of SGA for black women (aOR 0.85, 95\% Cl 0.76-0.95), but not whites ( $p$ for interaction $=0.02$ ). Clear racial disparities were found, but they were reduced modestly (LBW/SGA) or not at all (PTB/LGA) after CVD risk factors were adjusted for.
\end{abstract}

Conclusions: This analysis does not provide evidence for preconception cardiovascular risk being a strong contributor to racial disparities.

Keywords: Birth weight, low, Premature birth, Infant, small for gestational age, Cholesterol, Glucose, Continental population groups

\section{Background}

In the United States, blacks have roughly double the risk of infant mortality of other ethnic groups [1], due largely to preterm birth and fetal growth restriction. This disparity persists across populations with comparable access to health care and in otherwise low-risk groups, such as military populations, those with health insurance, and women with higher education and low initial medical risk [2-4]. Disparities in birth outcomes are mirrored in cardiovascular health. Black women have higher cardiovascular risk than other racial/ethnic

\footnotetext{
* Correspondence: eharvill@tulane.edu

${ }^{1}$ Department of Epidemiology, Tulane School of Public Health and Tropical Medicine, 1440 Canal St. Ste. 2001, \#8318, New Orleans, LA 70112-2715, USA Full list of author information is available at the end of the article
}

groups [5], including higher blood pressure and diabetes [6]. In NHANES, black women of childbearing age had higher systolic blood pressure, diastolic blood pressure, and glycated hemoglobin than other groups [7].

Recently there have been calls for more attention to preconception and interconceptional health in order to improve birth outcomes [8-11], including as a strategy to reduce black-white disparities [12, 13], in part because black women have an increased risk of preconception hypertension and diabetes [14]. Women with chronic hypertension who become pregnant are at higher risk of preterm birth and small-for-gestational-age $[15,16]$, while women with diabetes who become pregnant are at higher risk of preterm birth [16-18] and large-for-gestational-age/ macrosomia [19]. Some studies indicate that preconception 
cardiovascular health outside clinical disease also impacts pregnancy health: higher preconception blood pressure has been associated with lower birth weight [20], while both low and high cholesterol have been associated with poor pregnancy outcome [20, 21]. In addition, preconception glucose levels are associated with increased birthweight [20]. In our analysis of the Cardiovascular Risk in Young Finns Study [22], higher pre-pregnancy triglycerides were associated with a higher risk of hypertensive disorders, pre-eclampsia, and gestational diabetes, while higher blood pressure was associated with preterm birth and small-for-gestational-age.

Still, few studies have examined preconception cardiovascular health and birth outcomes [21], and some of the largest are limited to Scandinavian populations [20, 22]. While some studies have examined clinical comorbidities as predictors of birth outcomes in black women [23], few have assessed subclinical measures. In this study, we examine how pre-pregnancy cardiovascular risk factors are associated with birth outcomes in the Bogalusa Heart Study, a biracial study of cardiovascular health. The research questions are a) are pre-pregnancy cardiovascular risk factors associated with birth outcomes in this cohort; b) do any associations between these risk factors and the outcomes differ between African-American and white women? Based on the results of the analyses of those questions, we then examined whether pre-pregnancy cardiovascular health contribute to racial disparities in birth outcomes.

\section{Methods}

The Bogalusa Heart Study is a long-running study of childhood, adolescent, and now adult cardiovascular health, founded by Dr. Gerald Berenson in 1973 [24]. Participants were initially recruited from schools in the Bogalusa, Louisiana, area at ages 3-18. Over time, additional waves of data collection were performed, adding additional participants up to adulthood. Currently, participants are largely in their 40s through 60s, and follow-up for cardiovascular and early aging parameters continues. The average age at first visit was 8.5 for black women and 8.6 for white women, $p=0.32$.

As part of a larger study of cardiovascular and reproductive health ("Bogalusa Babies"), female participants were linked to their children's birth certificates for Louisiana, Mississippi, and Texas births from 1982 to 2009. The 1982-1989 records contained fewer variables for linkage than later years; observations that matched on four variables (year of birth, last name, Soundex code for last name, and race) were confirmed by visual comparison of addresses. From 1990 to 2009, a three stage linkage process was used, including deterministic record linkage based on maternal social security number (SSN), and probabilistic linkage when SSN was unavailable.
Five thousand, nine hundred and- ten women/girls participated in BHS at least once during the study. Of those, 3263 were linked to birth certificate data, representing a linkage of approximately $65 \%$ of the likely births (as approximately 10-15\% of women do not give birth). Participants linked to birth records were more likely to be black ( $37 \%$ vs. $35 \%$ ), had more study visits, had a younger average age at first visit (8.8 vs. 10.5), were less likely to smoke (35\% vs. $38 \%$ ), and had statistically lower mean BMIs (19.9 vs. 20.3) and blood pressure (101.8 vs. 102.8) (Harville et al., under review). Among white women, those whose parents had a high school education, rather than more or less education, were most likely to be linked, while among black women, likelihood of linkage fell with increased parental education. Among the smaller group with information about adult education, higher education was associated with increased likelihood of linkage among both black and white women. Three thousand and ninety-five women had at least one screening as a child, which occurred prior to the first pregnancy in the dataset. Two thousand, seven hundred and sixty-three screenings included a fasting blood samples; 2691 of these had data for analysis of lipids, insulin, and glucose. (More detail on missing data for covariates or individual risk factors is found in the tables). If a woman had multiple pregnancies, the first linked pregnancy was used, and analysis was limited to singleton births.

\section{Exposures}

Blood pressure levels were measured on the right arm of subjects in a relaxed, sitting position by two trained observers (3 replicates each). Systolic blood pressure and diastolic blood pressure were recorded using a mercury sphygmomanometer. The fifth Korotkoff phase was used for diastolic blood pressure. The mean values of the readings were used for analysis.

Fasting blood samples were drawn for lipids and glucose analysis. Prior to 1987, serum total cholesterol and triglyceride levels were determined by a Technicon AutoAnalyzer II (Technicon Instrument, Tarrytown, NY). From 1987 to 1996, cholesterol and triglyceride levels were determined by enzymatic procedures on the Abbott VP instrument (Abbott Laboratories, Chicago, IL) and on the Hitachi 902 Automatic Analyzer (Roche Diagnostics, Indianapolis, IN) after 1996. Serum lipoprotein cholesterols were analyzed by using a combination of heparin-calcium precipitation and agar-agarose gel electrophoresis procedures. Both chemical and enzymatic procedures met the performance requirements of the Lipid Standardization Program of the Centers for Disease Control and Prevention, which has routinely monitored the precision and accuracy of cholesterol and triglyceride measurements since 1973. Measurements on CDC-assigned quality control 
samples showed no consistent bias over time within or between surveys.

From 1981 to 1991, plasma glucose was measured by a glucose oxidase method using a Beckman Glucose Analyzer (Beckman Instruments, Palo Alto, CA). Since then, it has been measured enzymatically as part of a multichemistry (SMA20) profile.

Measurements were made by laboratory technicians blinded to participants' risk factors. Ten percent blind duplicate samples are selected, prior to blood drawing. The intraclass correlation coefficient for blind duplicate samples ranged from 0.92 for glucose to 0.99 for total cholesterol.

Birth outcomes were taken from measures on the birth certificates. Low birthweight (LBW) was defined as birthweight $<2500 \mathrm{~g}$, preterm birth (PTB) as birth $<37$ weeks (obstetric estimate, when available); small for gestational age (SGA) was defined as <10th percentile for gestational age (percentiles based on study population) and large for gestational age (LGA) as >90th percentile for gestational age. Report of both birthweight and gestational age on birth certificates have been found to be highly accurate $[25,26]$. A secondary analysis looked at birthweight as a continuous outcome.

Covariates were chosen a priori based on factors known to be associated with exposure and outcome [27, 28]. Race was recorded as white or black at the initial BHS visit. Later follow-ups and birth certificate data with more extensive options indicated that this was consistent with the racial/ethnic self-categorization of almost all participants ( $<10$ women had Hispanic ethnicity marked on the birth certificate).

Age at pregnancy was calculated from participant's date of birth. Data on parity, weight gain, maternal education, and smoking were taken from the birth certificate data. BMI at time of visit was calculated from measured height and weight: participants were measured in duplicate and the average of the measures was used. Adequacy of prenatal care was assessed using the Kotelchuck index [29], and categorized as inadequate, intermediate, adequate, and adequate plus.

\section{Analysis}

Cardiovascular measures at the visit closest in time but prior to the pregnancy (based on an estimated last menstrual period 40 weeks before birthdate) were examined as predictors. Logistic regression was used for dichotomous measures. Models were adjusted for variables that were associated with the outcome at $p<0.20$ : these varied by outcome but included age, race, smoking, parity, maternal education, adequacy of prenatal care, BMI at time of visit, age at time of Bogalusa screening, and years between Bogalusa screening and birth. Due to the strong correlation between BMI and cardiovascular risk factors, results are presented adjusted for BMI alone, then with adjustment for all factors. In addition to stratified models, combined models were run with an interaction term for race to examine differences between white and black participants. Results are presented stratified by race. As some studies have found non-linear associations between cardiovascular risk factors and birth outcomes [21], quadratic terms were also examined. Quadratic BMI was examined as a potential confounder, to assess possible non-linear confounding by BMI, but this term was neither statistically predictive nor did it change the effect estimate. We attempted to determine whether results were different when limited to those whose study visit was closer in time to the pregnancy, but sample size was relatively small $(n=586,217$ black, 369 white for those with a measure within 5 years of pregnancy) and results became too imprecise to judge whether this group differed from the main sample.

Racial disparities in birth outcomes were examined, first, unadjusted, then adjusted for the same confounders identified in the previous analysis. Finally, results were presented adjusted for these confounders as well as cardiovascular risk factors identified as predictors of birth outcomes in this or other analyses, including quadratic associations. As the associations found in this analysis were relatively weak, no formal mediation analysis was performed.

Participants' parents provided informed consent for child visits and adult participants provided their own informed consent for BHS measures. The Institutional Review Boards (IRB) of Tulane University (IRB ID\#256406), the State Department of Health and Hospitals of Louisiana, and the Texas Department of State Health Services approved the linkage protocol (Mississippi deferred to the Tulane IRB). The linkage was conducted under a waiver of consent, as it was deemed minimal risk and infeasible without the waiver.

\section{Results}

The study population was approximately one-third black and two-thirds white (Table 1). The majority of the linked pregnancies were first births, although $30 \%$ were not. Smoking during pregnancy was listed for $13 \%$. The average age at visit prior to pregnancy was 13 yrs. (range 4-38) and average time between study visit and pregnancy was 10.8 years (range $0.8-33$ ). Mean and median age at included pregnancy were 24.2 and 23.0.

Only a few cardiovascular risk factors were associated with birth outcomes. Triglycerides were associated with higher risk of LBW among whites (aOR 1.05, 95\% 1.01-1.10; Table 2); the effect estimate was very similar although not statistically significant for blacks (1.07, 0.97-1.19). Higher glucose was associated with a reduction in risk of SGA for black women 
Table 1 Participants in the Bogalusa Heart Study linked to birth certificates ( $N=3095)$

\begin{tabular}{|c|c|c|c|c|c|c|c|}
\hline & \multicolumn{2}{|c|}{ Overall study population } & \multicolumn{2}{|c|}{ Black $(n=1139)$} & \multicolumn{2}{|c|}{ White $(n=1956)$} & \multirow{2}{*}{$\begin{array}{l}p^{-} \\
\text {value }\end{array}$} \\
\hline & $\mathrm{N}$ & $\%$ & $\mathrm{~N}$ & $\%$ & $\mathrm{~N}$ & $\%$ & \\
\hline parity & & & & & & & $<0.01$ \\
\hline 1 & 2116 & 68.4 & 760 & 65.5 & 1384 & 70.3 & \\
\hline 2 & 630 & 20.4 & 229 & 19.7 & 410 & 20.8 & \\
\hline 3 & 243 & 7.9 & 106 & 9.1 & 137 & 7.0 & \\
\hline $4+$ & 104 & 3.3 & 66 & 5.7 & 38 & 1.9 & \\
\hline education & & & & & & & $<0.01$ \\
\hline$<$ high school & 780 & 25.2 & 343 & 29.6 & 448 & 22.7 & \\
\hline high school graduate & 1190 & 38.5 & 474 & 40.9 & 732 & 37.2 & \\
\hline some college & 575 & 18.6 & 219 & 18.9 & 361 & 18.3 & \\
\hline college \& beyond & 547 & 17.7 & 124 & 10.7 & 429 & 21.8 & \\
\hline married & & & & & & & $<0.01$ \\
\hline yes & 1638 & 53.0 & 256 & 22.1 & 1398 & 71.0 & \\
\hline no & 1452 & 47.0 & 903 & 77.9 & 571 & 29.0 & \\
\hline smoking & & & & & & & $<0.01$ \\
\hline yes & 376 & 12.8 & 380 & 12.8 & 328 & 17.4 & \\
\hline \multirow[t]{2}{*}{ no } & 2566 & 87.2 & 2595 & 87.2 & 1559 & 82.6 & \\
\hline & N & mean + SD & $\mathrm{N}$ & mean + SD & N & mean + SD & \\
\hline age at screening & 3095 & $13.0+6.7$ & 1139 & $12.5+6.4$ & 1956 & $13.3+6.8$ & $<0.01$ \\
\hline time from screening (yrs) & 3095 & $10.8+5.8$ & 1139 & $10.1+5.3$ & 1956 & $11.1+6.0$ & $<0.01$ \\
\hline maternal age & 3095 & $24.2+5.4$ & 1139 & $23.0+5.4$ & 1956 & $24.9+5.3$ & $<0.01$ \\
\hline pregnancy weight gain (lbs) & 2645 & $30.8+13.6$ & 930 & $29.0+13.8$ & 1715 & $31.7+13.4$ & $<0.01$ \\
\hline BMI & 3089 & $20.1+5.5$ & 1136 & $20.4+5.9$ & 1953 & $20.0+5.2$ & 0.08 \\
\hline systolic blood pressure & 3090 & $102.0+10.5$ & 1136 & $102.4+11.1$ & 1954 & $101.8+10.1$ & 0.11 \\
\hline diastolic blood pressure & 3090 & $63.1+9.7$ & 1136 & $62.7+10.5$ & 1954 & $63.3+9.2$ & 0.13 \\
\hline \multicolumn{8}{|l|}{ fasted only: } \\
\hline cholesterol & 2691 & $170.4+30.9$ & 976 & $173.2+31.7$ & 1715 & $168.7+30.3$ & $<0.01$ \\
\hline triglycerides & 2691 & $77.2+45.9$ & 976 & $66.1+29.9$ & 1715 & $83.5+51.8$ & $<0.01$ \\
\hline insulin & 2098 & $11.2+8.4$ & 777 & $12.4+10.6$ & 1321 & $10.5+6.6$ & $<0.01$ \\
\hline glucose & 2447 & $78.8+16.0$ & 888 & $77.5+17.7$ & 1559 & $79.4+14.9$ & 0.01 \\
\hline LDL-C & 2688 & $103.0+28.1$ & 974 & $103.9+28.5$ & 1714 & $102.4+27.9$ & 0.21 \\
\hline \multirow[t]{2}{*}{$\mathrm{HDL}-\mathrm{C}$} & 2690 & $56.7+16.4$ & 975 & $60.4+16.0$ & 1715 & $54.5+16.3$ & $<0.01$ \\
\hline & $\mathrm{N}$ & $\%$ & $\mathrm{~N}$ & $\%$ & $\mathrm{~N}$ & $\%$ & \\
\hline Low birthweight (full-term only) & 91 & 3.3 & 52 & 5.2 & 39 & 2.2 & $<0.01$ \\
\hline Preterm birth & 297 & 9.6 & 131 & 11.5 & 166 & 8.5 & $<0.01$ \\
\hline Small for gestational age & 353 & 11.4 & 182 & 16.0 & 171 & 8.7 & $<0.01$ \\
\hline Large for gestational age & 298 & 9.6 & 64 & 5.6 & 234 & 12.0 & $<0.01$ \\
\hline
\end{tabular}

(aOR 0.86, 95\% CI 0.79-0.95; Table 3), but not whites ( $\mathrm{p}$ for interaction $=0.02$ ). No associations were found with PTB (Table 4) or LGA (Table 5). Results were similar for birthweight as a continuous outcome (Additional file 1: Table S1).
A quadratic association was found with systolic blood pressure, indicating higher risk for LBW and SGA at lower and higher levels ( $p<0.05$ for quadratic term).

Finally, we directly assessed whether cardiovascular risk might contribute to racial disparities. Racial 


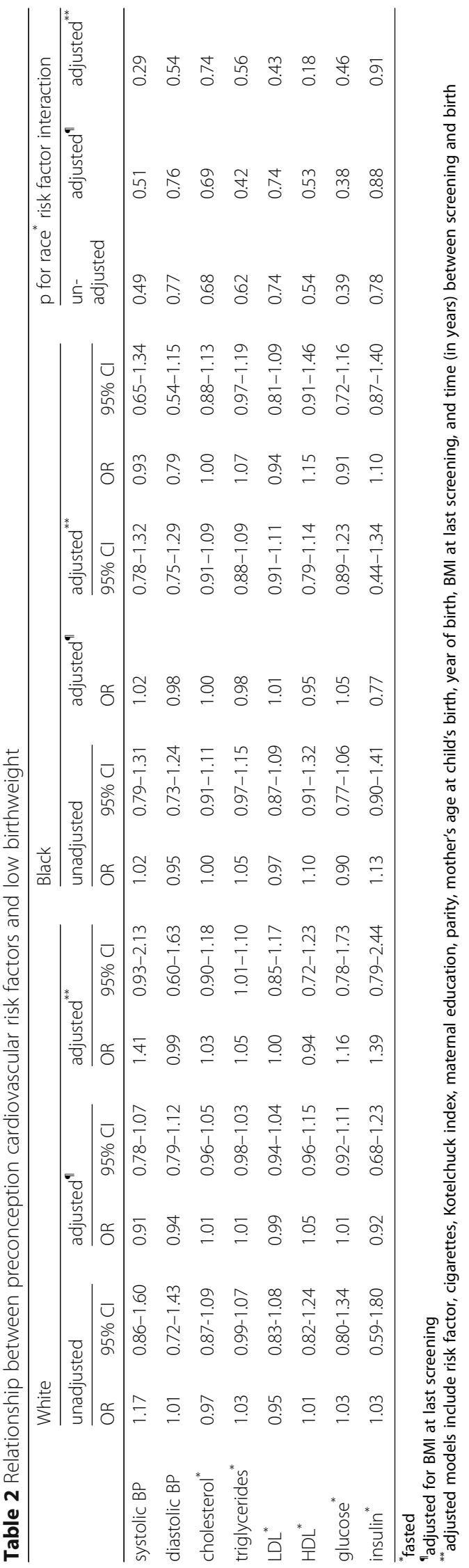


Table 3 Relationship between preconception cardiovascular risk factors and small-for-gestational-age

\begin{tabular}{|c|c|c|c|c|c|c|c|c|c|c|c|c|c|c|c|}
\hline & \multicolumn{6}{|c|}{ white } & \multicolumn{6}{|c|}{ black } & \multicolumn{3}{|c|}{$p$ for race ${ }^{*} \mathrm{RF}$ interaction } \\
\hline & \multicolumn{2}{|c|}{ unadjusted } & \multicolumn{2}{|c|}{ adjusted" } & \multicolumn{2}{|c|}{ adjusted $^{\ddagger}$} & \multicolumn{2}{|c|}{ unadjusted } & \multicolumn{2}{|c|}{ adjusted $^{\natural}$} & \multicolumn{2}{|c|}{ adjusted $^{\ddagger}$} & \multirow[t]{2}{*}{ unadjusted } & \multirow[t]{2}{*}{ adjusted" } & \multirow[t]{2}{*}{ adjusted $^{\ddagger}$} \\
\hline & OR & $95 \% \mathrm{Cl}$ & OR & $95 \% \mathrm{Cl}$ & OR & $95 \% \mathrm{Cl}$ & OR & $95 \% \mathrm{Cl}$ & OR & $95 \% \mathrm{Cl}$ & OR & $95 \% \mathrm{Cl}$ & & & \\
\hline systolic BP & 0.97 & $0.83-1.14$ & 1.06 & $0.88-1.27$ & 1.08 & $0.88-1.32$ & 0.96 & $0.83-1.11$ & 0.99 & $0.84-1.17$ & 1.03 & $0.85-1.25$ & 0.87 & 0.88 & 0.51 \\
\hline diastolic BP & 0.85 & $0.72-1.01$ & 0.89 & $0.73-1.08$ & 0.84 & $0.66-1.06$ & 0.93 & $0.80-1.09$ & 0.96 & $0.80-1.13$ & 1.02 & $0.84-1.26$ & 0.44 & 0.45 & 0.69 \\
\hline cholesterol $^{*}$ & 1.00 & $0.95-1.06$ & 1.01 & $0.95-1.07$ & 1.01 & $0.95-1.08$ & 0.96 & $0.91-1.02$ & 0.96 & $0.91-1.02$ & 0.96 & $0.90-1.02$ & 0.30 & 0.28 & 0.15 \\
\hline triglycerides $^{*}$ & 1.00 & $0.96-1.03$ & 1.00 & $0.97-1.04$ & 0.99 & $0.95-1.04$ & 1.02 & $0.97-1.08$ & 1.04 & $0.98-1.11$ & 1.04 & $0.97-1.11$ & 0.32 & 0.24 & 0.32 \\
\hline $\mathrm{LDL}^{*}$ & 1.00 & $0.94-1.06$ & 1.00 & $0.94-1.07$ & 0.99 & $0.92-1.06$ & 0.94 & $0.89-1.01$ & 0.96 & $0.90-1.02$ & 0.94 & $0.87-1.01$ & 0.36 & 0.35 & 0.22 \\
\hline $\mathrm{HDL}^{*}$ & 1.04 & $0.93-1.15$ & 1.02 & $0.92-1.14$ & 1.11 & $0.98-1.26$ & 0.97 & $0.87-1.08$ & 0.95 & $0.85-1.06$ & 0.99 & $0.87-1.12$ & 0.33 & 0.33 & 0.28 \\
\hline glucose ${ }^{*}$ & 1.05 & $0.92-1.20$ & 1.04 & $0.91-1.19$ & 1.11 & $0.95-1.29$ & 0.86 & $0.79-0.95$ & 0.85 & $0.77-0.94$ & 0.85 & $0.76-0.95$ & 0.02 & 0.02 & 0.02 \\
\hline insulin ${ }^{*}$ & 0.94 & $0.69-1.27$ & 1.02 & $0.74-1.41$ & 0.99 & $0.68-1.43$ & 1.06 & $0.90-1.25$ & 1.08 & $0.91-1.28$ & 1.06 & $0.89-1.27$ & 0.48 & 0.59 & 0.55 \\
\hline
\end{tabular}

disparities were clearly present in the sample: black women were at increased risk for LBW (Table 6; adjusted for non-cardiovascular risk factors, OR 3.84, 95\% CI 2.07-7.12), PTB (1.66, 1.24-2.23), and SGA (2.18, $1.61-2.96)$, and reduced risk for LGA $(0.35,0.25-0.48)$. Further adjustment for cardiovascular risk factors attenuated the LBW and SGA estimates by approximately $10 \%$.

\section{Discussion}

In this study, we attempted to determine the relationship between pre-pregnancy cardiovascular risk factors and disparities in birth outcomes. Although the expected racial disparities in cardiovascular risk factors and birth outcomes were found, there were only limited relationships among those factors. We found some evidence of inverse risk for associations between lipids and birthweight, largely among whites; previous studies have tended to find positive associations between pre-pregnancy lipids and birthweight [20]. Although not statistically significant, the size of the effect estimate for systolic blood pressure and birthweight was also consistent with previous studies in Scandinavian populations [20, 22]. Although previous studies of pre-pregnancy blood pressure have not found quadratic associations, such associations have been found in studies of blood pressure during pregnancy [30]. When associations were seen in black women, they tended to be protective, with higher glucose being associated with a reduced risk of LBW and SGA, consistent with previous studies [20]. A previous study of preterm birth found increased risk with both low and high levels of pre-pregnancy cholesterol, but did not find racial differences [21].

Preconception cardiovascular risk could lead to poorer birth outcomes by affecting placentation in the first trimester [21, 31, 32], increasing inflammation
[33], or producing epigenetic changes that carry into pregnancy [34, 35]. It could also increase the risk of complications such as pre-eclampsia and gestational diabetes [36-38]; vital records data often have limited validity for those complications and record them in a manner problematic for this type of analysis (e.g., grouping pre-pregnancy and gestational diabetes) [25, 26]. Racial disparities are also apparent in particularly pregnancy-induced hypertension and pre-eclampsia, and thus these complications could mediate an effect of cardiovascular risk on birth outcomes [39-41].

Strengths of the study include the prospective data collection; well-characterized cardiovascular risk factors; a fairly large, biracial cohort; and linkage to participants regardless of later participation. Limitations include the variation in time between the pregnancy and the measure, and the lack of information on cardiovascular risk during the pregnancy, which would assist in determining whether preconception cardiovascular risk provides any additional information beyond that determined during pregnancy. In addition, we are limited to those who were able to be linked to vital statistics data. Comparisons of those who are linked and who were not does not point to a strongly high- or low-risk profile in those who were excluded; still, this set of potential participants represents a group that has the potential to change the results if they had been able to be included. On balance, there are indicators that both high- and low-risk women may have been less likely to be included; this may have reduced the variability in the sample and thus limited our ability to find differences.

Measurement error per se - of the included measures - should be limited. BHS has rigorous quality control methods, including measurement in duplicate, throughout. Birth certificate data is generally good quality for preterm birth and low birthweight [42], 


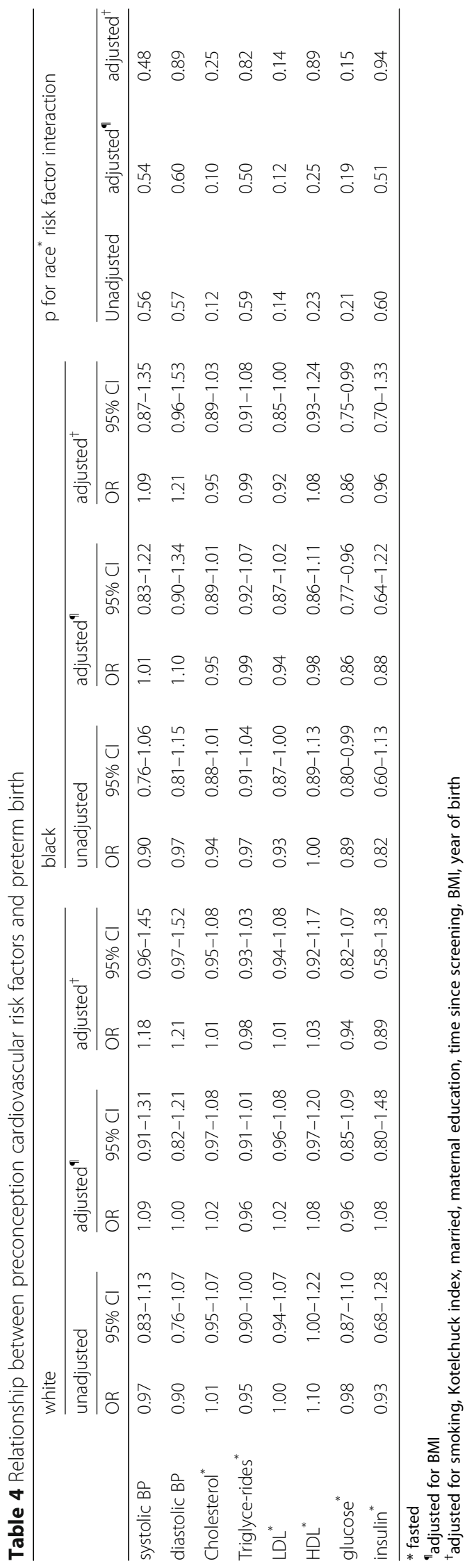


Table 5 Relationship between preconception cardiovascular risk factors and large-for-gestational-age

\begin{tabular}{|c|c|c|c|c|c|c|c|c|c|c|c|c|c|c|c|}
\hline & \multicolumn{6}{|c|}{ white } & \multicolumn{6}{|c|}{ black } & \multirow[t]{3}{*}{ unadjusted } & \multirow[t]{3}{*}{ adjusted } & \multirow[t]{3}{*}{ adjusted $^{\S}$} \\
\hline & \multicolumn{2}{|c|}{ unadjusted } & \multicolumn{2}{|c|}{ adjusted" } & \multicolumn{2}{|c|}{ adjusted $^{\S}$} & \multicolumn{2}{|c|}{ unadjusted } & \multicolumn{2}{|c|}{ adjusted" } & \multicolumn{2}{|c|}{ adjusted $^{\S}$} & & & \\
\hline & $\overline{O R}$ & $95 \% \mathrm{Cl}$ & $\overline{O R}$ & $95 \% \mathrm{Cl}$ & $\overline{O R}$ & $95 \% \mathrm{Cl}$ & $\overline{O R}$ & $95 \% \mathrm{Cl}$ & $\overline{O R}$ & $95 \% \mathrm{Cl}$ & $\overline{O R}$ & $95 \% \mathrm{Cl}$ & & & \\
\hline systolic BP & 1.04 & $0.91-1.19$ & 0.91 & $0.78-1.07$ & 0.86 & $0.72-1.02$ & 0.99 & $0.79-1.24$ & 1.02 & $0.78-1.32$ & 0.97 & $0.71-1.31$ & 0.72 & 0.69 & 0.66 \\
\hline diastolic BP & 1.07 & $0.92-1.25$ & 0.94 & $0.79-1.12$ & 0.91 & $0.75-1.10$ & 0.96 & $0.76-1.22$ & 0.98 & $0.75-1.29$ & 0.96 & $0.70-1.31$ & 0.45 & 0.48 & 0.49 \\
\hline cholesterol $^{*}$ & 1.02 & $0.98-1.07$ & 1.01 & $0.96-1.05$ & 1.02 & $0.97-1.08$ & 1.00 & $0.91-1.09$ & 1.00 & $0.91-1.09$ & 1.00 & $0.91-1.10$ & 0.69 & 0.71 & 0.57 \\
\hline triglycerides ${ }^{*}$ & 1.02 & $0.99-1.04$ & 1.01 & $0.98-1.03$ & 1.00 & $0.98-1.03$ & 0.97 & $0.88-1.08$ & 0.98 & $0.88-1.09$ & 1.00 & $0.89-1.11$ & 0.43 & 0.33 & 0.48 \\
\hline $\operatorname{LDL}^{*}$ & 1.01 & $0.96-1.06$ & 0.99 & $0.94-1.04$ & 1.01 & $0.95-1.06$ & 1.00 & $0.91-1.11$ & 1.01 & $0.91-1.11$ & 1.02 & $0.92-1.14$ & 0.96 & 0.96 & 0.93 \\
\hline $\mathrm{HDL}^{*}$ & 1.01 & $0.93-1.11$ & 1.05 & $0.96-1.15$ & 1.05 & $0.95-1.15$ & 0.96 & $0.80-1.15$ & 0.95 & $0.79-1.14$ & 0.88 & $0.71-1.09$ & 0.61 & 0.58 & 0.22 \\
\hline glucose ${ }^{*}$ & 0.99 & $0.89-1.09$ & 1.01 & $0.92-1.11$ & 0.97 & $0.88-1.07$ & 1.05 & $0.89-1.23$ & 1.05 & $0.89-1.23$ & 1.07 & $0.90-1.26$ & 0.51 & 0.59 & 0.30 \\
\hline insulin ${ }^{*}$ & 1.10 & $0.88-1.38$ & 0.92 & $0.68-1.23$ & 0.85 & $0.62-1.16$ & 0.86 & $0.55-1.34$ & 0.77 & $0.44-1.34$ & 0.74 & $0.42-1.31$ & 0.32 & 0.35 & 0.40 \\
\hline
\end{tabular}

* fasted

"adjusted for BMI

§adjusted for smoking, parity, time since screening, BMI, maternal age

although gestational age measurements may be of limited quality for the oldest women, as ultrasound dating was less consistent during the time period of their pregnancies [43]. However, measurement error still exists in the sense that a single risk factor measurement is representing a large time period, and the measurements were not taken at the same time point for every woman, compounding the degree of error. This error would tend to bias the results towards the null, and it is possible that we would see a greater effect with measurements nearer in time to the pregnancy; our sample size for this analysis was too small to provide much information on this point. Measurement of non-cardiovascular covariate data is potentially more problematic. Tobacco use tends to be underreported on birth certificates [44]. Adjustment for covariates is fairly limited, although the strongest risk factors that were likely to be associated with exposure and outcomes were included. Overall, residual confounding would likely bias away from the null. Similarly, if cardiovascular risk factors are acting as confounders of the race-birth outcome relationship, imperfect measurement could be leading to residual confounding and preventing full adjustment for those factors, suggesting that better measures would more fully attenuate the relationships. Although prior preterm birth and low birthweight are associated with the outcome, in most cases the cardiovascular measure would have occurred prior to that birth as well, so it is unlikely that adjustment for this risk factor would be valid [45].

\section{Conclusions}

Mechanisms underlying the persistence of racial disparities in birth outcomes continue to elude public health researchers. The findings presented in this study do not include strong patterns of association between lifetime cardiovascular risk profiles and racial differences in incidence of adverse birth outcomes despite sound theoretical plausibility. However, the ambiguity in our results underscores the need for more research that considers pre-pregnancy health status and biological pathways

Table 6 Racial disparities in birth outcomes and cardiovascular risk factors

\begin{tabular}{|c|c|c|c|c|c|c|}
\hline & \multicolumn{2}{|c|}{ unadjusted } & \multicolumn{2}{|c|}{ adjusted } & \multicolumn{2}{|c|}{ additionally adjusted for cardiovascular risk factors } \\
\hline & OR & $95 \% \mathrm{Cl}$ & OR & $95 \% \mathrm{Cl}$ & $\mathrm{OR}$ & $95 \% \mathrm{Cl}$ \\
\hline Low birthweight & 2.44 & $1.69-3.73$ & $3.84^{a}$ & $2.07-7.12$ & $3.32^{\mathrm{e}}$ & $1.52-7.21$ \\
\hline Preterm birth & 1.40 & $1.10-1.79$ & $1.66^{\mathrm{b}}$ & $1.24-2.23$ & $1.65^{f}$ & $1.19-2.30$ \\
\hline Small-for-gestational-age & 1.99 & $1.59-2.48$ & $2.18^{c}$ & $1.61-2.96$ & $1.95^{\mathrm{g}}$ & $1.37-2.76$ \\
\hline Large-for-gestational-age & 0.44 & $0.33-0.58$ & $0.35^{d}$ & $0.25-0.48$ & $0.32^{h}$ & $0.22-0.45$ \\
\hline
\end{tabular}

Adjusted for:

a(same adjustments as previous tables) smoking, Kotelchuck index, married, maternal education, time since screening, BMI, year of birth

${ }^{b}$ smoking, Kotelchuck index, maternal education, parity, maternal age, year of birth, time since screening, BMI

csmoking, Kotelchuck index, maternal education, parity, married, maternal age, time since screening, BMI

${ }^{d}$ smoking, parity, time since screening, BMI, maternal age

eprevious column + triglycerides, insulin, systolic blood pressure, systolic blood pressure-squared

previous column + glucose, LDL

${ }^{g}$ previous column + glucose, systolic blood pressure, systolic blood pressure-squared

$h_{\text {previous column }+ \text { glucose }}$ 
underlying racial disparities in birth outcomes. Future studies should aim for more precise measures and biological indicators of mechanism to improve our understanding of these outcomes.

\section{Additional file}

Additional file 1: Table S1. Relationship between preconception cardiovascular risk factors and continuous birthweight, the Bogalusa Heart Study. (DOCX $14 \mathrm{~kb})$

\section{Abbreviations}

BHS: Bogalusa Heart Study; BMI: Body mass index; HDL: High-density lipoprotein; LBW: Low birthweight; LDL: Low-density lipoprotein; LGA: Largefor-gestational-age; OR: Odds ratio; PTB: Preterm birth; SGA: Small-forgestational-age; SSN: Social Security Number

\section{Acknowledgements}

Richard Johnson and Judy Moulder at the Mississippi State Department of Health Chris Simmons and Jamie Huang at the Texas Department of State Health Services.

\section{Funding}

The Bogalusa Heart Study is supported by grants R01HD069587, R01HL016592, R01AG041200, P50HL015103, R01HD032194. This work was supported in part by U54 GM104940 from the National Institute of General Medical Sciences of the National Institutes of Health, which funds the Louisiana Clinical and Translational Science Center. The content is solely the responsibility of the authors and does not necessarily represent the official views of the National Institutes of Health.

\section{Availability of data and materials}

The datasets analyzed during the current study are not publicly available due to confidentiality/research subject protection but are available from the corresponding author on reasonable request complying with applicable ethical standards.

\section{Authors' contributions}

EWH conceived and wrote the paper, and supervised data linkage and analysis. LM advised on biostatistics and performed data analysis. TS constructed relevant datasets and participated in data analysis. MEW performed the data linkage and assisted in paper conceptualization. LAB supervised data collection and study design. All authors revised the paper critically for content and contributed to study and analysis design. All authors read and approved the final manuscript.

\section{Ethics approval and consent to participate}

Participants' parents provided informed consent for child visits and adult participants provided their own informed consent for BHS measures. The Institutional Review Boards (IRB) of Tulane University (IRB ID\#256406), the State Department of Health and Hospitals of Louisiana, and the Texas Department of State Health Services approved the linkage protocol (Mississippi deferred to the Tulane IRB). The linkage was conducted under a waiver of consent, as it was deemed minimal risk and infeasible without the waiver.

\section{Consent for publication}

Not applicable

\section{Competing interests}

EWH is an associate editor of this journal.

\section{Publisher's Note}

Springer Nature remains neutral with regard to jurisdictional claims in published maps and institutional affiliations.

\section{Author details}

'Department of Epidemiology, Tulane School of Public Health and Tropical Medicine, 1440 Canal St. Ste. 2001, \#8318, New Orleans, LA 70112-2715, USA.
${ }^{2}$ Department of Global Biostatistics and Data Science, Tulane School of Public Health and Tropical Medicine, New Orleans, LA, USA. ${ }^{3}$ Department of Global Community Health and Behavioral Sciences, Tulane School of Public Health and Tropical Medicine, New Orleans, LA, USA.

Received: 10 February 2017 Accepted: 31 July 2018

Published online: 20 August 2018

\section{References}

1. Matthews TJ, Mac Dorman MF. Infant mortality statistics from the 2010 period linked birth/infant death data set. Natl Vital Stat Rep. 2013:62(8):1-26.

2. Hatch M, Berkowitz G, Janevic T, Sloan R, Lapinski R, James T, Barth WH Jr. Race, cardiovascular reactivity, and preterm delivery among active-duty military women. Epidemiology. 2006;17(2):178-82.

3. Whitehead N, Helms K. Racial and ethnic differences in preterm delivery among low-risk women. Ethn Dis. 2010;20(3):261-6.

4. Alexander GR, Kogan MD, Himes JH, Mor JM, Goldenberg R. Racial differences in birthweight for gestational age and infant mortality in extremely-low-risk US populations. Paediatr Perinat Epidemiol. 1999;13(2):205-17.

5. Finkelstein EA, Khavjou OA, Mobley LR, Haney DM, Will JC. Racial/ethnic disparities in coronary heart disease risk factors among WISEWOMAN enrollees. J Womens Health (Larchmt). 2004;13(5):503-18.

6. Kurian AK, Cardarelli KM. Racial and ethnic differences in cardiovascular disease risk factors: a systematic review. Ethn Dis. 2007;17(1):143-52.

7. Arbour MW, Corwin EJ, Salsberry PJ, Atkins M. Racial differences in the health of childbearing-aged women. MCN Am J Matern Child Nurs. 2012;37(4):262-8.

8. Posner SF, Broussard DL, Sappenfield WM, Streeter N, Zapata LB, Peck MG. Where are the data to drive policy changes for preconception health and health care? Womens Health Issues. 2008;18(6 Suppl):S81-6.

9. Berends AL, de Groot CJ, Sijbrands EJ, Sie MP, Benneheij SH, Pal R Heydanus R, Oostra BA, van Duijn CM, Steegers EA. Shared constitutional risks for maternal vascular-related pregnancy complications and future cardiovascular disease. Hypertension. 2008;51(4):1034-41.

10. Ashton DM, Lawrence HC 3rd, Adams NL 3rd, Fleischman AR. Surgeon General's conference on the prevention of preterm birth. Obstet Gynecol. 2009;113(4):925-30.

11. Shapiro-Mendoza CK, Barfield WD, Henderson Z, James A, Howse IL, Iskander J, Thorpe PG. CDC grand rounds: public health strategies to prevent preterm birth. MMWR Morb Mortal Wkly Rep. 2016;65(32):826-30.

12. Lu MC, Kotelchuck M, Hogan V, Jones L, Wright K, Halfon N. Closing the black-white gap in birth outcomes: a life-course approach. Ethn Dis. 2010; 20(1 Suppl 2):S2-62-76.

13. Ramey SL, Schafer P, DeClerque JL, Lanzi RG, Hobel C, Shalowitz M, Chinchilli $V$, Raju TN. The preconception stress and resiliency pathways model: a multi-level framework on maternal, paternal, and child health disparities derived by community-based participatory research. Matern Child Health J. 2015;19(4):707-19.

14. D'Angelo D, Williams L, Morrow B, Cox S, Harris N, Harrison L, Posner SF, Hood JR, Zapata L. Preconception and interconception health status of women who recently gave birth to a live-born infant--pregnancy risk assessment monitoring system (PRAMS), United States, 26 reporting areas, 2004. MMWR Surveill Summ. 2007:56(10):1-35.

15. Odell CD, Kotelchuck M, Chetty VK, Fowler J, Stubblefield PG, Orejuela M, Jack BW. Maternal hypertension as a risk factor for low birth weight infants: comparison of Haitian and African-American women. Matern Child Health J. 2006:10(1):39-46.

16. Sibai BM, Caritis SN, Hauth JC, MacPherson C, VanDorsten JP, Klebanoff M, Landon M, Paul RH, Meis PJ, Miodovnik M, et al. Preterm delivery in women with pregestational diabetes mellitus or chronic hypertension relative to women with uncomplicated pregnancies. The National institute of Child Health and Human Development Maternal- Fetal Medicine Units Network. Am J Obstet Gynecol. 2000;183(6):1520-4.

17. Kock K, Kock F, Klein K, Bancher-Todesca D, Helmer H. Diabetes mellitus and the risk of preterm birth with regard to the risk of spontaneous preterm birth J Matern Fetal Neonatal Med. 2010:23(9):1004-8.

18. Melamed N, Chen R, Soiberman U, Ben-Haroush A, Hod M, Yogev Y. Spontaneous and indicated preterm delivery in pregestational diabetes mellitus: etiology and risk factors. Arch Gynecol Obstet. 2008;278(2):129-34.

19. Simmons D. Diabetes and obesity in pregnancy. Best Pract Res Clin Obstet Gynaecol. 2011;25(1):25-36. 
20. Romundstad PR, Davey Smith G, Nilsen TI, Vatten LJ. Associations of prepregnancy cardiovascular risk factors with the offspring's birth weight. Am J Epidemiol. 2007;166(12):1359-64.

21. Catov JM, Ness RB, Wellons MF, Jacobs DR, Roberts JM, Gunderson EP. Prepregnancy lipids related to preterm birth risk: the coronary artery risk development in young adults study. J Clin Endocrinol Metab. 2010; 95(8):3711-8.

22. Harville EW, Viikari JS, Raitakari OT. Preconception cardiovascular risk factors and pregnancy outcome. Epidemiology. 2011;22(5):724-30.

23. Ehrenthal DB, Jurkovitz C, Hoffman M, Kroelinger C, Weintraub W. A population study of the contribution of medical comorbidity to the risk of prematurity in blacks. Am J Obstet Gynecol. 2007;197(4):409. e401-406

24. Berenson GS. Bogalusa heart study: a long-term community study of a rural biracial (black/white) population. Am J Med Sci. 2001;322(5):293-300.

25. Vinikoor LC, Messer LC, Laraia BA, Kaufman JS. Reliability of variables on the North Carolina birth certificate: a comparison with directly queried values from a cohort study. Paediatr Perinat Epidemiol. 2010;24(1):102-12.

26. Zollinger TW, Przybylski MJ, Gamache RE. Reliability of Indiana birth certificate data compared to medical records. Ann Epidemiol. 2006;16(1):1-10.

27. Goldenberg RL, Culhane JF, lams JD, Romero R. Epidemiology and causes of preterm birth. Lancet. 2008;371(9606):75-84

28. Kramer MS. The epidemiology of low birthweight. Nestle Nutr Inst Workshop Ser. 2013;74:1-10.

29. Kotelchuck M. The adequacy of prenatal care utilization index: its US distribution and association with low birthweight. Am J Public Health. 1994; 84(9):1486-9.

30. Zhang J, Klebanoff MA. Low blood pressure during pregnancy and poor perinatal outcomes: an obstetric paradox. Am J Epidemiol. 2001;153(7):642-6.

31. Thorp JM. Placental vascular compromise: unifying the etiologic pathways of perinatal compromise. Curr Prob Obstet Gynecol. 2001;24(6):197-220.

32. Kroener $L$, Wang ET, Pisarska MD. Predisposing factors to abnormal first trimester placentation and the impact on fetal outcomes. Semin Reprod Med. 2016;34(1):27-35

33. McDade TW, Borja JB, Largado F, Adair LS, Kuzawa CW. Adiposity and chronic inflammation in young women predict inflammation during normal pregnancy in the Philippines. J Nutr. 2016;146(2):353-7.

34. St Fleur M, Damus K, Jack B. The future of preconception care in the United States: multigenerational impact on reproductive outcomes. Ups J Med Sci. 2016:1-5.

35. Steegers-Theunissen RP, Twigt J, Pestinger V, Sinclair KD. The periconceptional period, reproduction and long-term health of offspring: the importance of one-carbon metabolism. Hum Reprod Update. 2013; 19(6):640-55.

36. Egeland GM, Klungsoyr K, Oyen N, Tell GS, Naess O, Skjaerven R. Preconception cardiovascular risk factor differences between gestational hypertension and preeclampsia: cohort Norway study. Hypertension. 2016; 67(6):1173-80.

37. Baumfeld Y, Novack L, Wiznitzer A, Sheiner E, Henkin Y, Sherf M, Novack V. Pre-conception dyslipidemia is associated with development of preeclampsia and gestational diabetes mellitus. PLoS One. 2015;10(10): e0139164.

38. Harville EW, Juonala M, Viikari JS, Raitakari OT. Preconception metabolic indicators predict gestational diabetes and offspring birthweight. Gynecol Endocrinol. 2014;30(11):840-4.

39. Baraban E, McCoy L, Simon P. Increasing prevalence of gestational diabetes and pregnancy-related hypertension in Los Angeles County, California, 1991-2003. Prev Chronic Dis. 2008;5(3):A77.

40. Cabacungan ET, Ngui EM, McGinley EL. Racial/ethnic disparities in maternal morbidities: a statewide study of labor and delivery hospitalizations in Wisconsin. Matern Child Health J. 2012;16(7):1455-67.

41. Mbah AK, Alio AP, Marty PJ, Bruder K, Wilson R, Salihu HM. Recurrent versus isolated pre-eclampsia and risk of feto-infant morbidity outcomes: racial/ ethnic disparity. Eur J Obstet Gynecol Reprod Biol. 2011;156(1):23-8.

42. Martin JA, Wilson EC, Osterman MJ, Saadi EW, Sutton SR, Hamilton BE. Assessing the quality of medical and health data from the 2003 birth certificate revision: results from two states. Natl Vital Stat Rep. 2013;62(2):1-19.
43. Campbell S. A short history of Sonography in obstetrics and Gynaecology. Facts Views Vis Obgyn. 2013;5(3):213-29.

44. Northam S, Knapp TR. The reliability and validity of birth certificates. J Obstet Gynecol Neonatal Nurs. 2006:35(1):3-12.

45. Howards PP, Schisterman EF, Poole C, Kaufman JS, Weinberg CR. "Toward a clearer definition of confounding" revisited with directed acyclic graphs. Am J Epidemiol. 2012;176(6):506-11.
Ready to submit your research? Choose BMC and benefit from:

- fast, convenient online submission

- thorough peer review by experienced researchers in your field

- rapid publication on acceptance

- support for research data, including large and complex data types

- gold Open Access which fosters wider collaboration and increased citations

- maximum visibility for your research: over $100 \mathrm{M}$ website views per year

At BMC, research is always in progress.

Learn more biomedcentral.com/submissions 